\title{
Changing Students' Perception of Mathematics Through Active Learning
}

\author{
Alexandra Kurepa ${ }^{1, *}$, John Paul Roop ${ }^{1} \&$ Kossi Edoh ${ }^{1}$ \\ ${ }^{1}$ Department of Mathematics, North Carolina A\&T State University, Greensboro, NC 27411, \\ USA
}

*Corresponding author: Department of Mathematics, North Carolina A\&T State University, Greensboro, NC 27411, USA. E-mail: kurepa@ncat.edu

Received: December 1, 2018 Accepted: January 3, 2019 Published: March 7, 2019

doi:10.5296/ije.v11i1.13983 URL: https://doi.org/10.5296/ije.v11i1.13983

\begin{abstract}
In this paper we present results from a study of the effects of active learning on students' perception of mathematics through their engagement, satisfaction, and perceived performance in the class. We use an active learning model, modified for underprepared STEM students, in our redesigned calculus course and compare students' responses to those of students in traditionally taught sections of the same course. Our results show that introducing active learning has positively changed students' perspective on mathematics in gateway mathematics courses. Students strongly agree that they are more engaged in the course and that the structure of active learning facilitates discussion in the classroom. Moreover, as we document student perceptions of learning and confirm the findings by disaggregating students' exam performance both in an active learning and in a traditionally taught class, we find that the assessment result conducted confirmed students' perception of improved learning.
\end{abstract}

Keywords: Active learning, Perception, College mathematics 


\section{Introduction}

With growing interest from government and businesses in hiring professionals in Science, Technology, Engineering, and Mathematics (STEM), the need to train minority students with strong mathematical and analytical skills to be competitive in today's global economy has increased. In the last decade, there has been widespread interest in determining how to improve the retention, graduation, and success rates of students in the STEM fields. Graham, Frederick, Byars-Winston, Hunter, and Handelsman (2013) have suggested that one reason more institutions have not implemented (more) retention strategies in the STEM fields is that it is unclear what policies or procedures would work.

Retention and success in various "gatekeeper" courses, such as pre-calculus and calculus, is of primary importance for students in all STEM fields as well as many others. The failure rates among underserved students in gatekeeper courses -- such as pre-calculus and calculus -- are alarming (Twigg, 2005). This is especially the case for minority and underrepresented students. Even among those students who complete specific courses, some fail to master the core concepts and knowledge needed for follow-up courses (Schoenfeld, 1992).

As Twigg (2005) notes, "Indeed, 45 percent of African-American students and 39 percent of Hispanic students, on average, leave four-year institutions within six years without earning degrees, compared with 33 percent of white students and 26 percent of Asian-American students." Clearly, making significant improvement in gatekeeper courses can have major impact on student success and retention. One of the reasons for these success rates for students in the United States could be time actually spent studying, practicing, and participating in the work required. Chickering and Gamson (1987) stated that a good practice includes measuring the time students spent on task. The average US college student spends less than one hour studying for each one hour spent in class, which is far below their peers in other developed countries such as the UK (Gardiner, 1997).

\section{Active Learning}

One way to increase success in these areas could be through innovative teaching. Over the last decade, significant changes have taken place in the way mathematics is taught in general education mathematics courses. One of the prominent developments in this regard is the development and the implementation of various "active learning" strategies. These strategies and tactics appear in areas of broad interest and relevance to students in many disciplines in STEM and beyond - such as business and accounting (Freeman \& Eddy, 2014).

A variety of pedagogical techniques and strategies have been employed under the label of "active learning." Bonwell and Eison (1991) define active learning in the following way:

(1) Students are involved in more than listening

(2) Less emphasis is placed on transmitting information and more on developing students' skills 
(3) Students are involved in higher-order thinking (analysis, synthesis, evaluation)

(4) Students are engaged in activities (e.g. reading, discussing, writing)

(5) Greater emphasis is placed on students' exploration of their own attitudes and values

Research has shown that minority students tend to perform better in an active learning environment as opposed to the more traditional lecture structures. (Eddy \& Hogan, 2014; Ross, 2014; Graham, Frederick, Byars-Winston, Hunter, \& Handelsman, 2013; Edoh \& Tang, 2007). Furthermore, our research has shown that students perform better when given a choice between an active learning environment and a more traditional learning environment (Roop, Edoh, \& Kurepa, 2018). Other areas of active learning still remain to be explored, especially within the context of minority and underrepresented groups.

\section{Goals and Research Questions}

The main goal of this paper is to analyze the effect that using active learning has on minority and underrepresented students' perception of mathematics. In particular, this study focuses on a group of mathematically underprepared STEM students in a gateway calculus course.

We propose the following research questions.

1. Do students have greater engagement with active learning classes?

2. Do students have a greater sense of satisfaction with active learning?

3. Do students feel that they will perform better in active learning classes?

Specifically, we try to determine the effect active learning (ACL) in the classroom has on the following three areas.

\subsection{Engagement}

ACL is known to engage students through active listening, reflecting, talking and reading. By doing things on their own, students develop the habit of thinking about what they are doing (Bonwell \& Eison, 1991). When students learn the material on their own initially, it increases their level of participation in the class. Distributed involvement throughout the course improves the long-term retention of knowledge (Dunlosky, Rawson, Marsh, Nathan, \& Willingham, 2013). Creating an environment that focuses on mutual respect, a commitment to learning, collaboration, and dignity for all promotes the engagement of all students. We want to determine whether ACL increases student's willingness to put forth effort to complete the activities, increases interest and curiosity about the course subject, and whether it improves communication/interactivity with the instructor and other students, making collaboration with classmates easier. 


\subsection{Satisfaction}

ACL improves the classroom environment such that students perceive the class as a community, thereby increasing their motivation and satisfaction. Students feel comfortable taking risks in engaging in communication, thinking, and problem solving. There are indications that individual or group-learning processes using active learning pedagogy increase some types of student satisfaction (Ellis, 2004). We want to determine whether ACL can be perceived to be successful in facilitating multiple types of learning activities, is perceived to offer greater flexibility and time efficiency in studying, is perceived as fun/exciting, and whether it is perceived as a comfortable learning environment.

\subsection{Performance}

The provision of an interdependent environment has been shown to be important for the performance of under-represented minority students (Stephens, Fryberg, Markus, \& Johnson, 2012). Requiring students to read course materials before class gives the instructor time to develop students' higher-order cognitive skills in class. Working through real-world problems attempts to improve student performance (Carini, Kuh, \& Klein, 2006). We want to determine whether students see ACL as beneficial to their performance, does it appear to them to deepen the learning and understanding of the course topics and concepts, and whether students perceive that it improves their scores on assignments and exams.

\section{Background and Methodology}

North Carolina A \& T State University is currently ranked as the number one HBCU in the country by U.S. News \& World Report. The University has a STEM focus and awards the largest number of engineering and mathematics degrees to African American students in the US. Therefore, NC A \& T serves as an excellent location to conduct this research.

The redesigned course considered in this paper is a general education calculus course targeted at students in Technology, Business, Agriculture and the Health Sciences. The overwhelming majority of the students are from protected minority groups. Based on the specific needs of our student population, the calculus for business and technology course (annual enrollment of over 800) has been redesigned by implementing active learning techniques and the use of additional technology as teaching tools. The main goal of this redesign is to improve student success, retention, and attitudes towards learning.

The redesign of the Calculus for Business and Technology course follows that of the Student-Centered Active Learning Environment with the Upside-down Pedagogies model, which was developed by North Carolina State University. We have adopted the SCALE-UP (Beichner, Saul, Abbott, Morse, Deardorff, Allain, Bonham, Dancy, \& Risley, 2007) model for the course. The main distinction between SCALE-UP and traditional active learning ideas is the use of the active learning classroom, in which the classroom environment itself is altered to facilitate active learning (Park \& Choi, 2014). A workbook has been created for this course (Edoh, Roop, Park, \& Deeb, 2016) and published by Pearson Publishing. In addition, there 
are worksheets used during the interactive sessions. The questions on the worksheets are designed to reinforce students' understanding of the lecture materials.

Surveys are one of the most efficient ways to obtain the data needed to address the three research questions stated above. Surveys provide a scalable and relatively efficient approach for studying students' responses to classroom instruction, motivation related to learning and self-reflection. We developed and implemented a survey given to both an active learning section and a traditional lecture section of the same course during the same term. In order to compare students' perception of learning and performance with the students' class performance we gave both sections the same test and analyzed the responses.

\section{Results}

Survey results are given below including information on responses to relevant questions and two sets of diagrams.
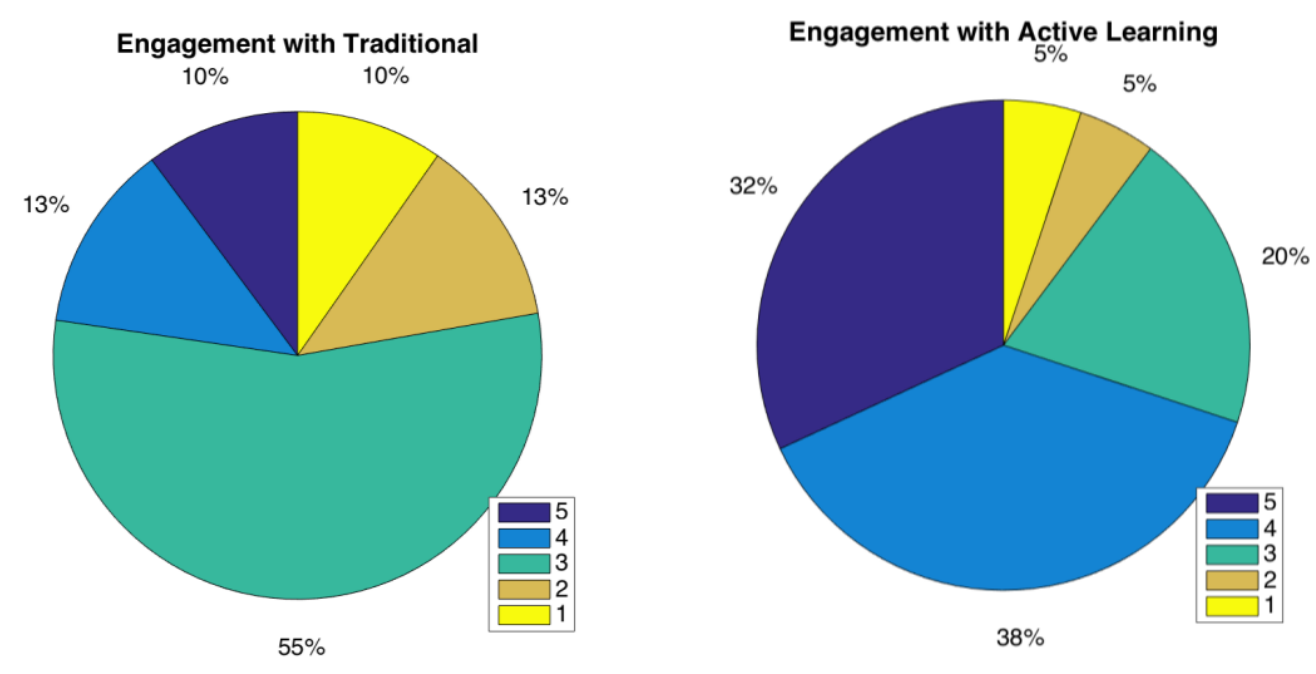

Figure 1. Perception of Engagement among Traditional and Active Learning Courses

\subsection{Student Perception of Engagement}

The overall mean of survey responses for questions related to the students' perception of engagement was 3.01 for traditional courses and 3.87 for active learning courses. The statement "made me feel like part of the class" received the highest score of 3.41 among traditional courses and the statement "increased my curiosity about the course subject" received the lowest score of 2.63 among the traditional courses. The statement "increased my willingness to put forth effort to complete the activities" received the highest score of 4.37 among the active learning courses and the statement "promoted connection with the instructor through discussions" received the lowest score of 3.37 among the active learning courses. Figure 1 displays the results in a pie chart with results beginning in the north and proceeding in a counter clockwise fashion. The dark blue represents the number 5 - strongly agree, the light blue represents the number 4 - agree, the teal represents the number 3 - neither agree nor 


\section{Macrothink}

disagree, the brown represents the number 2 - disagree, and finally the yellow represents 1 strongly disagree.

\subsection{Student Perception of Satisfaction}

The overall mean of survey responses to the questions related to student perception of satisfaction was 2.94 for traditional courses and 3.69 for active learning courses. The statement "was an appropriate space in which to hold the course" received the highest score of 3.41 among traditional courses and the statement "facilitated interactive learning experiences" received the lowest score of 2.59 among the traditional courses. The statement "made it easier to collaborate with other students" received the highest score of 4.15 among the active learning courses and the statement "was fun" received the lowest score of 3.19 among the active learning courses. Figure 2 displays the results in a pie chart with results beginning in the north and proceeding in a counter clockwise fashion. The same color-coding is used.
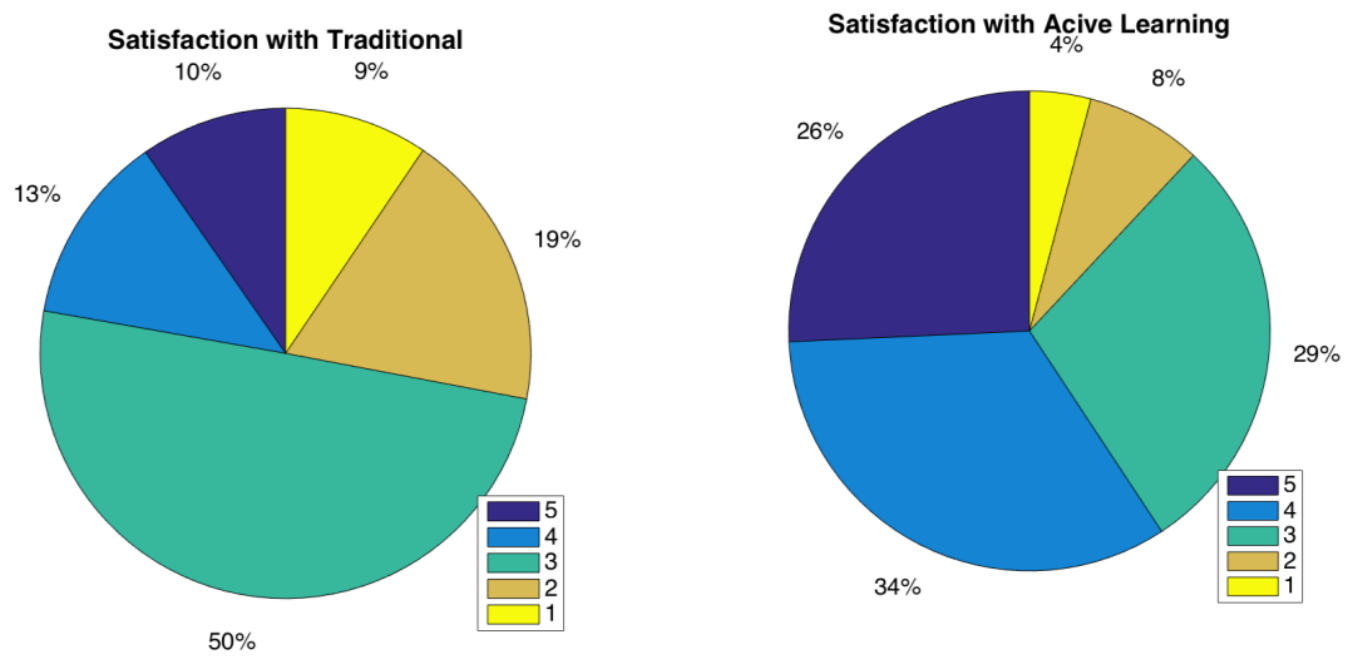

Figure 2. Perception of Satisfaction among Traditional and Active Learning Courses
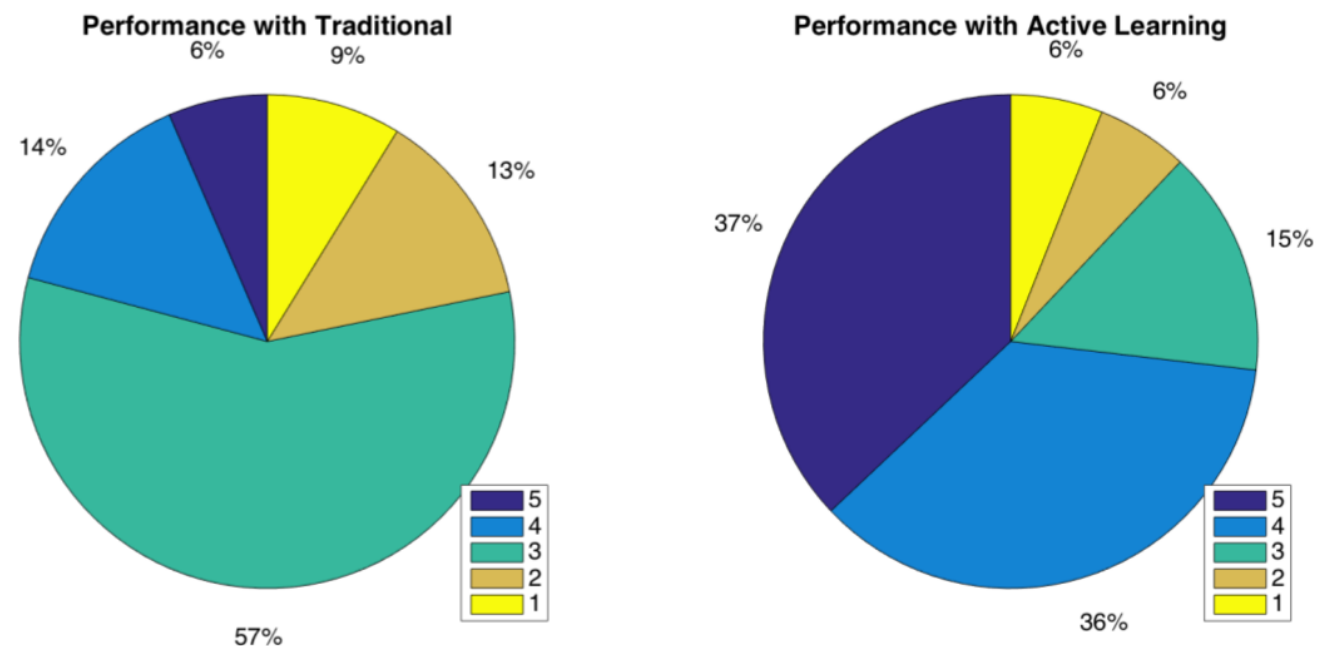

Figure 3. Perception of Performance among Traditional and Active Learning Courses 


\section{Macrothink}

\subsection{Student Perception of Their Performance}

The overall mean of survey responses for questions related to student perception of their performance was 2.97 for traditional courses and 3.92 for active learning courses. The statement "had impact on my grade in this class" received the highest score of 3.19 among traditional courses and the statement "helped me to do better on exams" received the lowest score of 2.85 among the traditional courses. The statement "increased my willingness to put forth effort to complete the activities" received the highest score of 4.19 among the active learning courses and the statement "helped me to do better on exams" received the lowest score of 3.70 among the active learning courses. Figure 3 displays the results in a pie chart with results beginning in the north and proceeding in a counter clockwise fashion. The same color-coding is used.

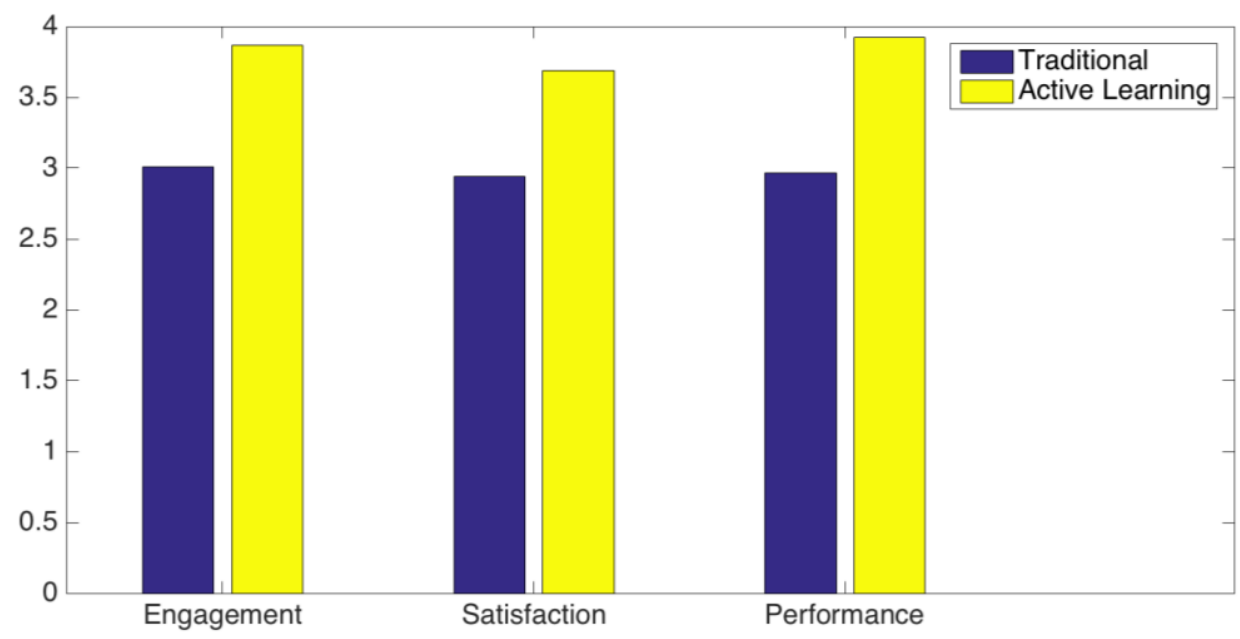

Figure 4. Bar Graph Showing the Average Survey Responses of Traditional and Active Learning Courses Broken Down into the Categories of Engagement, Satisfaction, and Performance

Therefore, as presented in Figure 4, the average survey responses for students in the traditional and active learning courses show by comparison a clear indication that students perceive active learning better in all three of the studied categories: student engagement, satisfaction and performance. These results positively answer and summarize our previously stated research questions 1,2 and 3.

\subsection{Verification of Increased Performance Using Common Scoring}

In addition to the students' perception that they perform better in an active learning class, there is also evidence that they do, in fact, perform better. Identical exam questions were given to courses with each teaching method and were classified as "basic" and "applied" problems. Basic questions were designed to test the mastery of mathematical techniques and concepts, while applied problems were more open-ended problems that tested student understanding of the concepts and their ability to apply the learned techniques to real world 
problems. Figure 5 gives the results for the common questions. Each question was assessed using a rubric with points assigned in the ranges 0-5. In the figure, a pie chart is used with the scores beginning in the north and proceeding in a counter clockwise fashion.

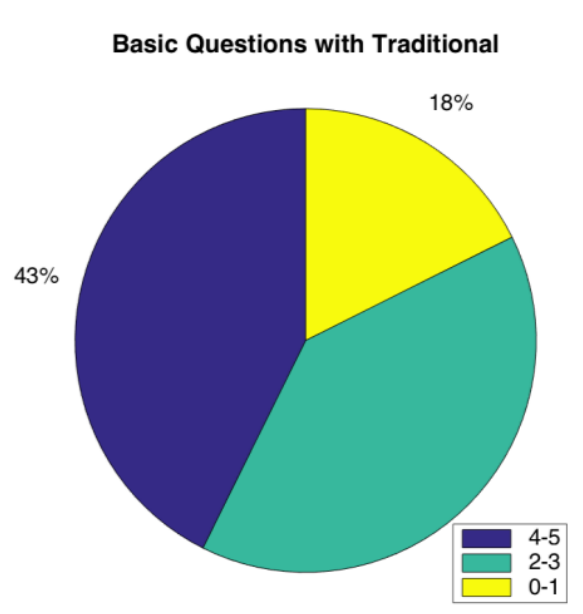

Applied Questions with Traditional

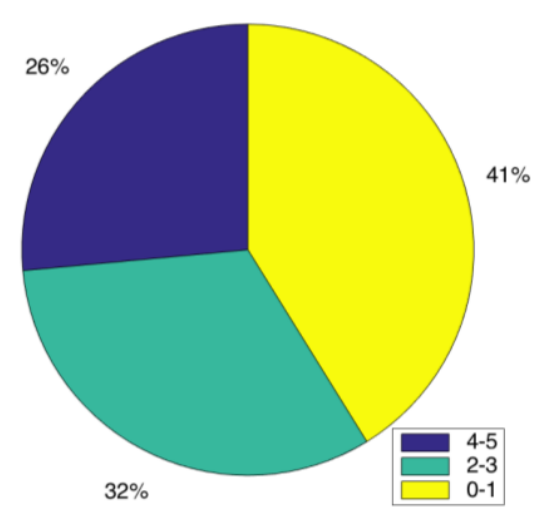

Basic Questions with Active Learning

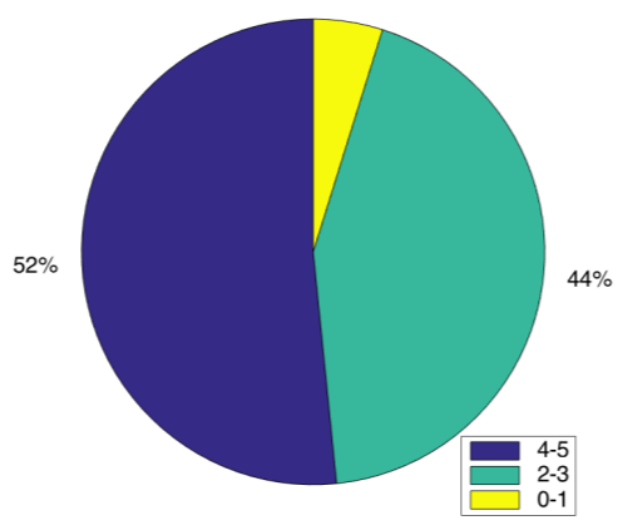

Applied Questions with Active Learning

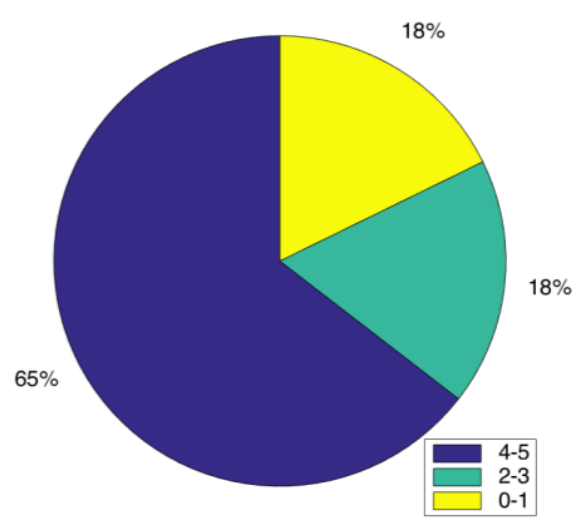

Figure 5. Pie Graphs Showing the Exam Scoring for Traditional (LEFT) versus Active Learning (RIGHT) Courses Using Basic (TOP) and Applied (BOTTOM) Questions

The results are broken down into three categories: dark blue represents a score of 4-5 on the question, teal represents a score of 2-3 on the question, and finally, yellow represents a score of $0-1$ on the question.

The results showed higher scores for those students in the active learning class. The top row in Figure 5 compares question scores for questions categorized as basic questions. The bottom row compares question scores for questions categorized as applied questions. We can see from the results that there is a significant difference between the student's performance when it comes to basic questions - in this case finding derivatives and integrals, critical points, or identifying the relative maximum and minimum using the first and second 
derivative test. Student performance on the basic, rote material seems to not be enhanced very much by active learning methodologies. The large gain comes when examining students' performance on so-called applied problems. These are more complex, word problems where students have to use calculus to solve constrained optimization, related rates, or calculus applications in business and finance. By disaggregating the kinds of problems scored, we can clearly see the gain from the active learning classroom - the active discussion with other students and the instructor leads to higher level reasoning, more connecting of concepts, and improved critical thinking skills.

\section{Conclusion}

Our results show that introducing active learning has positively changed students' perspective of mathematics in gateway mathematics courses. Students strongly agree that the new course design is beneficial for their learning. They strongly agree that the active learning course structure facilitates interaction and discussion with fellow students. Students also strongly agree that they are more engaged in the course and state their willingness to put forth effort to complete the activities. The most important result that came from the survey is that students strongly agree that their performance in the class as well as their learning and understanding of the material has improved with active learning. By implementing common test questions administered to both the active learning class and the traditional class, the assessment result conducted confirmed students' perception of improved learning.

\section{Acknowledgements}

Dr. Kurepa was partially supported by NSF award number DUE-1259900. Dr. Edoh was partially supported by NSF HRD-1719498 and NSA H98230-18-1-0097.

\section{References}

Beichner, R. J., Saul, J. M., Abbott, D. S., Morse, J. J., Deardorff, D., Allain, R. J., Bonham, S.W., Dancy, M.H., \& Risley, J. S. (2007). The student-centered activities for large enrollment under- graduate programs (SCALE-UP) project, Research-based reform of university physics, 1(1), 2-39.

Bonwell, C. C., \& Eison, J. A. (1991). Active Learning: Creating Excitement in the Classroom. ASHE-ERIC Higher Education Reports. ERIC Clearinghouse on Higher Education, Washington.

Carini, R. M., Kuh, G. D., \& Klein, S. P. (2006). Student Engagement and Student Learning: Testing the Linkages. Research in Higher Education, 47(1), 1-32.

Chickering, A. W., \& Gamson, Z. E. (1987). Seven principles for good practice in under-graduate education, American Association for Higher Education, 39, 3-6. 
Dunlosky J., Rawson K. A., Marsh E. J., Nathan M. J., \& Willingham D. T. (2013). Improving Students' Learning with Learning Techniques Promising Directions from Cognitive and Educational Psychology, Psychological Science in the Public Interest, 14(1), 4-58. https://doi.org/10.1177/1529100612453266

Eddy, S. L., \& Hogan, K. A. (2014). Getting under the hood: How and for whom does increasing course structure work?, CBE Life Sci. Educ., 13(3), 453-468. https://doi.org/10.1187/cbe.14-03-0050

Edoh, K. D., \& Tang, G. (2007). Online homework delivery systems for calculus. SITE' Proceedings, San Antonio, 318-323, San Antonio.

Edoh, K. D., Roop, J. P., Park, C., \& Deeb, A. (2016). Calculus for Business and Technology - Workbook. Pearson Publishing.

Ellis, A. K. (2005). Research on educational innovations. Larchmont, NY: Eye on Education.

Ellis, K. (2004). The impact of perceived teacher confirmation on receiver apprehension. motivation and learning. Communication Education, 53, 1-20. https://doi.org/10.1080/0363452032000135742

Freeman, S., Eddy, S. L., McDonough, M., Smith, M. K., Okoroafor, N., Jordt, H., \& Wenderoth, M. P. (2014). Active learning increases student performance in science, engineering, and mathematics. Proceedings of the National Academy of Sciences, 111(23), 8410-8415, Chicago. https://doi.org/10.1073/pnas.1319030111

Gardiner, L. E. (1997). Redesigning higher education: Producing dramatic gains in student learning. ASHE-ERIC Higher Education Reports, 23(7), Washington.

Graham, M. J., Frederick, J., Byars-Winston, A., Hunter, A. B., \& Handelsman, J. (2013). Increasing persistence of college students in STEM. SCIENCE, 341, 1455-1456. https://doi.org/10.1126/science.1240487

Lawrence, S. et al. (2001). Persistence of Web References in Scientific Research. Computer, 34, 26-31. http://dx.doi.org/10.1109/2.901164

Park, E. L., \& Choi, B. K. (2014). Transformation of classroom spaces: Traditional versus active learning classroom in colleges. Higher Education, 68(5), 749-771. https://doi.org/10.1007/s10734-014-9742-0

Roop, J. P., Edoh, K., \& Kurepa A. (2018). Instructional Selection of Active Learning and Traditional Courses Increases Student Achievement in College Mathematics. Journal of Education and Learning, 7(5), 11-19. https://doi.org/10.5539/jel.v7n5p11

Ross, T. F. (Dec. 12, 2014). How black students tend to learn science: Transforming a lecture into a more active experience is one possible way of fixing STEM's diversity dilemma, The Atlantic. Retrieved from http://www.theatlantic.com/education/archive/2014/12/how-black-students-tend-to-learn -science/383387/ 


\section{Macrothink}

Schoenfeld, A. H. (1992). Learning to think mathematically: Problem solving, metacognition, and sense making in mathematics. In D. Grouws (Ed.), Handbook for research on mathematics teaching and learning (p. 334-370). New York: Macmillan.

Smith, Joe. (1999). One of Volvo's core values. Retrieved July 7, 2007 from http://www.volvo.com/environment/index.htm

Stephens N. M., Fryberg S. A., Markus H. R., \& Johnson C. S. (2012). Unseen disadvantage: how American universities' focus on independence undermines the academic performance of first-generation college students. Journal of Personality and Social Psychology, 102, 1178-1197. https://doi.org/10.1037/a0027143

Strunk, W., Jr., \& White, E. B. (1979). The elements of style (3rd ed.). New York: Macmillan, (Chapter 4).

Twigg, C. (2005). Increasing success for underserved students: Redesigning introductory courses. Retrieved from http://www.thencat.org/Monographs/IncSuccess.htm

Van der Geer, J., Hanraads, J. A. J., \& Lupton R. A. (2000). The art of writing a scientific article. Journal of Scientific Communications, 163, 51-59.

\section{Copyright Disclaimer}

Copyright for this article is retained by the author(s), with first publication rights granted to the journal.

This is an open-access article distributed under the terms and conditions of the Creative Commons Attribution license (http://creativecommons.org/licenses/by/3.0/). 